\title{
Game 3d Perjuangan Rakyat Surabaya Dalam Pertempuran 10 November 1945 Dengan Belanda Menggunakan Unreal Engine
}

\author{
Ade Fahmi Armanda ${ }^{1}$, Maulana Rizqi ${ }^{2}$ \\ ${ }^{1}$ Program Studi Sistem Komputer, Fakultas Ilmu Komputer, Universitas Narotama \\ e-mail:ade.fahmi@mhs.fasilkom,narotama.ac.id \\ ${ }^{2}$ Program Studi Sistem Komputer, Fakultas Ilmu Komputer, Universitas Narotama \\ e-mail: maulana.rizqi@narotama.ac.id
}

\begin{abstract}
Abstrak
Sejarah tidak menjanjikan dan tidak akan memberikan keuntungan material, tapi tidak berarti kesadaran sejarah jauh dari nilai guna. Sejarah bisa memberi semangat bagi kehidupan berbangsa di masa sekarang dan masa datang. Nilai guna tidak harus berwujud dalam bentuk materi, dalam banyak hal, manfaat sesuatu tidak selamanya berbentuk materi. Untuk tetap membuat tiap warga negara memiliki rasa cinta tanah air di era globalisasi yang membuat semua budaya dan perkembangan teknologi informasi komunikasi termasuk game dapat tersebar luas yang mempengaruhi kehidupan. Untuk itu diperlukan pengingat akan sejarah perjuangan para pahlawan, agar tidak melupakan sejarah perjuangan pahlawanpahlawan memperjuangkan kemerdekaan Indonesia.
\end{abstract}

Kata kunci: Sejarah perjuangan, pertempuran, Game

3D Game Surabaya People's Struggle in the Battle of November 10, 1945 with the Netherlands Using Unreal Engine

\begin{abstract}
History is not promising and will not provide material benefits, but does not mean that historical awareness is far from use value. History can encourage the life of the nation in the present and the future. Use value does not have to be tangible in the form of material, in many cases, the benefits of something do not always take the form of material. To continue to make every citizen have a sense of love for the motherland in the era of globalization which makes all cultures and developments in information communication technology including games widely spread that affect life. This requires a reminder of the history of the struggle of the heroes, so as not to forget the history of the struggle of the heroes to fight for Indonesian independence.
\end{abstract}

Keywords: History of struggles, battle, game 


\section{Pendahuluan}

Sejarah bisa dijadikan pembelajaran untuk sebuah bangsa dalam melangkah ke masa depan yang masih penuh dengan ketidakpastian. Tapi, permasalahannya adalah mau atau tidaknya masyarakat untuk belajar dari masa lalu atau sejarahnya. Kesadaran sejarah tidak menjanjikan dan tidak akan memberikan keuntungan material. Tapi, tidak berarti kesadaran sejarah jauh dari nilai guna.

Sejarah bisa memberi semangat bagi kehidupan berbangsa di masa sekarang dan masa datang. Nilai guna tidak harus berwujud dalam bentuk materi. Dalam banyak hal, manfaat sesuatu tidak selamanya berbentuk materi. Kesadaran sejarah untuk mempertahankan identitas bangsa di saat globalisasi budaya dunia. Dengan kesadaran sejarah akan terbangun nilai-nilai nasionalisme, dan patriotisme (Lamanto, 2016).

Nation berasal dari bahasa latin natio, yang dikembangkan dari kata nascor (saya dilahirkan), maka pada awalnya nation (bangsa) dimaknai sebagai "sekelompok orang yang dilahirkan di suatu daerah yang sama". Nasionalisme pada mulanya terkait dengan rasa cinta sekelompok orang pada bangsa, bahasa dan daerah asal usul semula. Rasa cinta seperti itu disebut semangat patriotisme. Jadi, pada mulanya nasionalisme dan patriotisme itu sama maknanya

Untuk tetap membuat tiap warga negara memiliki rasa cinta tanah air di era globalisasi yang membuat semua budaya dan perkembangan teknologi informasi komunikasi termasuk game dapat tersebar luas yang mempengaruhi kehidupan. Untuk itu diperlukan pengingat akan sejarah perjuangan para pahlawan. Agar tidak melupakan sejarah perjuangan pahlawan-pahlawan memperjuangkan kemerdekaan Indonesia. Game adalah software yang saat ini sedang berkembang. Berbagai jenis game dengan tampilan yang menarik dapat menjadi sarana untuk refreshing (Syuhada, 2014).

Game perjuangan rakyat Surabaya dalam pertempuran 10 November 1945 dengan Belanda bertujuan untuk mengenalkan senjata senjata yang digunakan rakyat Surabaya saat pertempuran itu. Senjata yang digunakan yaitu, bambu runcing. Pemain bisa memilih senjata yang akan digunakan untuk melawan Musuh atau Belanda. Musuh dalam Game ini, termasuk NPC atau Non Playable Character. NPC adalah objek dalam Game yang tidak bisa dikendalikan oleh Pemain, tetapi dikendalian oleh program komputer. Dengan NPC, permainan akan lebih seru atau tidak monoton, 
Membuat Pemain akan merasa tertantang. Game perjuangan rakyat Surabaya dalam pertempuran 10 November 1945 dengan Belanda ini dibuat menggunakan unreal engine. Alasan memilih unreal engine, karena jika ada update versi, file yang sudah dibuat di versi sebelumnya masih bisa dibuka dan dilanjutkan pengembangannya di versi terbaru atau versi yang berbeda.

Masalah yang dapat teridentifikasi yang pertama yaitu bagaimana membuat game 3d perjuangan rakyat suarabaya dalam pertemupran 10 November 1945 dengan belanda, membuat asset senjata senjata pertempuran, bagaimana membuat character dan memprogram NPC agar Game lebih seru atau menatang, dan bagaimana membuat setting latar Game dalam suasana pertempuran.

\section{Pembahasan}

\section{Pengertian Game}

Game diklasifikasikan menjadi dua bagian besar yaitu game fisik dan game elektronik. Game adalah salah satu bentuk hiburan yang dapat dijadikan sebagai penyegar pikiran dari kepenatan akibat dari padatnya aktivitas sehari-hari. (Ricyono et al., 2019). Video game atau game elektronik adalah salah satu hiburan interaktif yang menggunakan perangkat elektronik (Moshinsky, 1959; Prasetiyo et al., 2018; Walelang et al., 2015). Game adalah bagian yang tidak bisa dipisahkan dari keseharian anak-anak (Miranda et al., 2018). Game fisik dalam kehidupan sehari-hari contohnya adalah lompat tali, dan petak umpet.

Dimensi adalah ukuran yang meliputi : panjang, luas, tinggi, lebar, dan sebagainya (Setiawan, 2016). Dimensi tiga merupakan dimensi yang memiliki tiga unsur dimensi yaitu panjang, lebar, dan juga tinggi. Benda-benda dimensi tiga dapat bergerak bebas ke arah kanan, kiri, atas, bawah, depan, dan belakang. Benda-benda dimensi tiga sering juga disebut dengan istilah bangun ruang. Salah satu ciri utama benda dimensi tiga adalah dapat diisi dengan benda - benda tertentu atau dengan kata lain memiliki volume. Game Perjuangan Rakyat Surabaya Dalam Pertempuran 10 November 1945 ini memiliki unsur panjang, tinggi, dan lebar sehingga dapat dikatakan sebagai game tiga dimensi. 


\section{Mobile Software}

Mobile adalah kata sifat yang berarti dapat bergerak atau dapat digerakkan dengan bebas dan mudah (Efendi, 2018). Software merupakan suatu perangkat yang berfungsi ialah sebagai pengatur aktivitas kerja komputer serta seluruh intruksi yang mengarah pada sistem komputer serta juga menjembatani interaksi antara user dengan komputer (Ramadhani, 2020). Software merupakan sebuah perangkat operasi kerja untuk bisa menjalankan berbagai komponen pada hardware yang mempunyai sifat maya (tidak terlihat) namun bermanfaat bagi user-nya (Muzakkiyah, 2019). Software merupakan nyawa dari sebuah hardware atau juga komputer disebabkan karna tanpa adanya perangkat lunak tersebut maka komputer hanyalah sebuah hardware yang mati serta tidak dapat digunakan (Ibeng, 2020). Unreal Engine adalah software terintegrasi pengembang game untuk merancang dan membangun game, simulasi, dan visualisasi (Epic Games inc., 2020).

Salah satu platform mobile yang ada adalah Android. Android adalah generasi baru paltform mobile, platform yang memberikan kebebasan pengembang untuk melakukan pengembangan sesuai dengan yang diharapkan (Lubis et al., 2015). Android adalah sistem operasi mobile yang tumbuh ditengah sistem operasi lainnya yangberkembang dewasa ini (Irawan et al., 2018). Android adalah perangkat bergerak pada sistem operasi untuk telpon seluler yang berbasis linux (Rasjid, 2010).

\section{Pathfinding}

Penerapan pathfinding meliputi analisis sebuah peta untuk menemukan nilai terbaik dalam perjalanan dari satu titik ke titik yang lain. Lintasan terbaik disini dapat diartikan banyak nilai dan menggunakan kriteria seperti lintasan terpendek, nilai lintasan paling sedikit, serta lintasan yang aman. Salah satu hal yang utama dalam pathfinding adalah menghindari halangan. Karena dengan kemampuan menghindari halangan maka kita akan mendapatkan hasil yang lebih baik dalam melakukan pathfinding. Algoritma pathfinding diimplementasikan ke Nonplayer Character (NPC) Follower pada video game agar pergerakan menuju ketujuan yaitu player bisa lebih maksimal. NPC Follower sendiri adalah karakter di game yang merupakan aliansi dari player atau musuh tetapi di jalankan oleh komputer (Harsadi, 2016) 


\section{Perancangan Game}

Game 3d Perjuangan Rakyat Surabaya Dalam Pertempuran 10 November 1945 ini dibuat dengan tahapan-tahapan sebagai berikut:

a. Perancangan

Pada tahap perancangan terdiri dari perancangan setting/latar cerita, Senjata,

\section{Player, Non Playable Character}

b. Implementasi

Pada tahap implementasi terdiri dari perancangan yang dilakukan menggunakan Unreal Engine. Unreal Engine adalah software terintegrasi pengembang game untuk merancang dan membangun game, simulasi, dan visualisasi.

c. Pengujian

Pada tahap pengujian penelitihan ini menggunakan pengujian waktu tempuh. Waktu tempuh dari titik awal ke titik akhir.

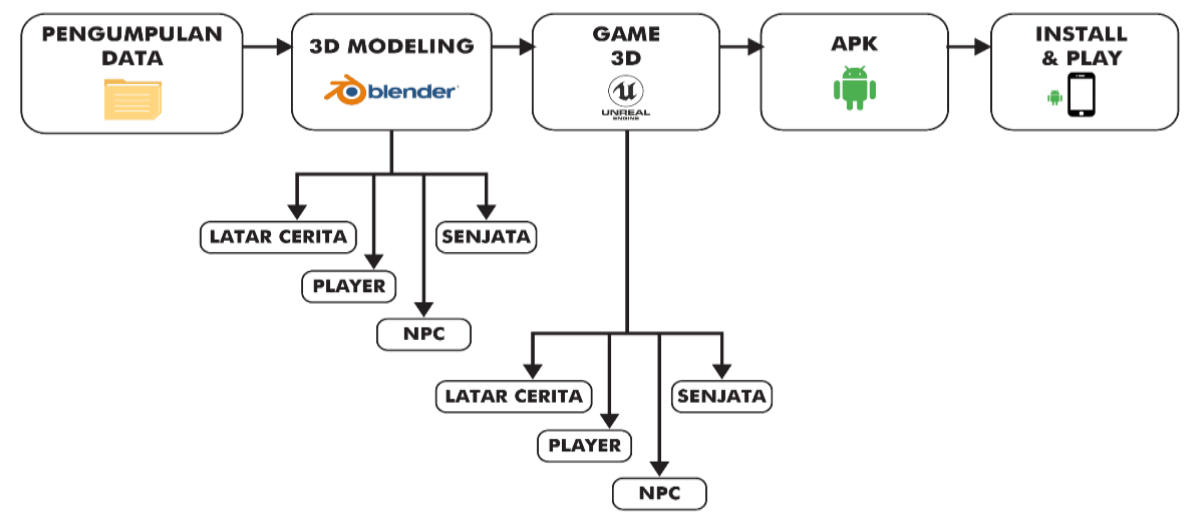

Gambar 1. Gambar diagram alur proses penelitian. 
Ade Fahmi Armanda, Maulana Rizqi

Game 3d Perjuangan Rakyat Surabaya Dalam Pertempuran 10 November 1945 Dengan Belanda Menggunakan Unreal Engine

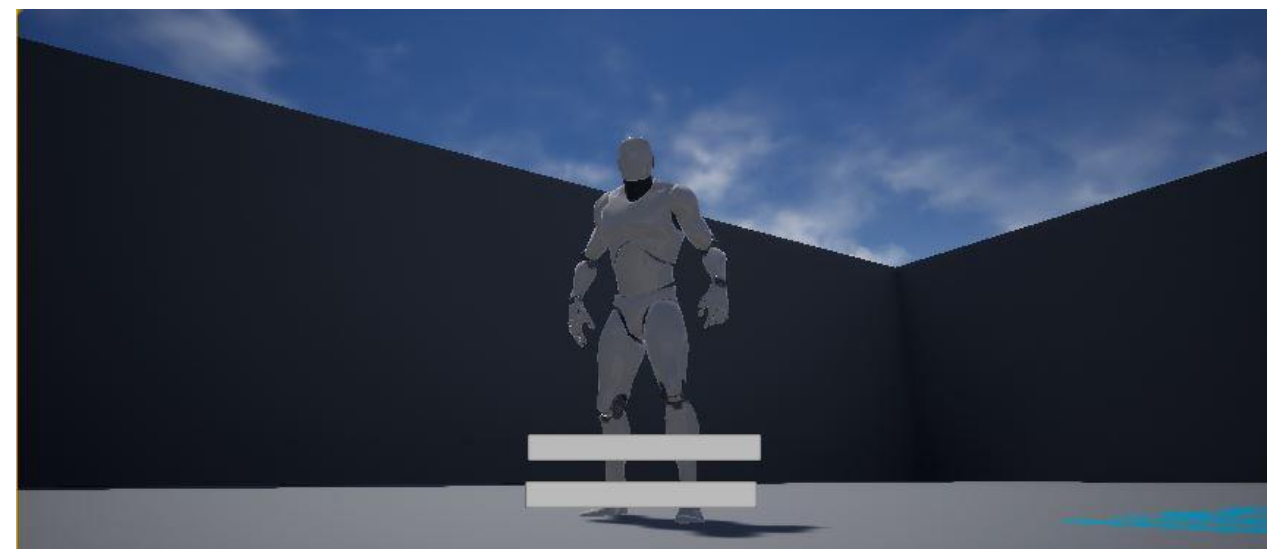

Gambar 2. Player

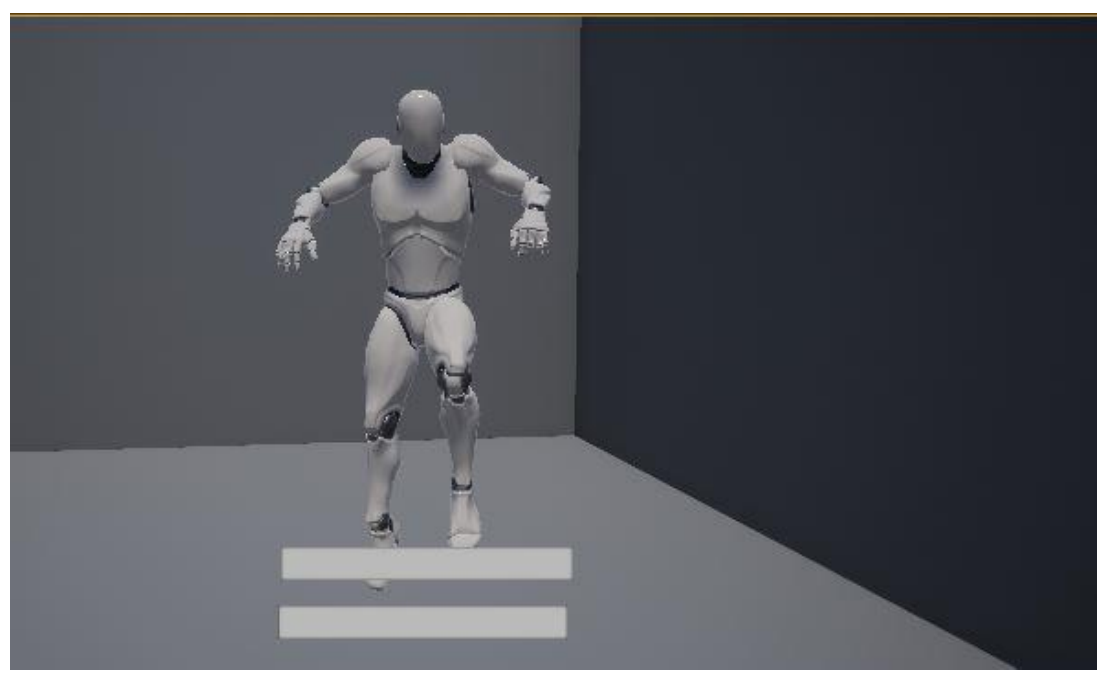

Gambar 3. Player melompat

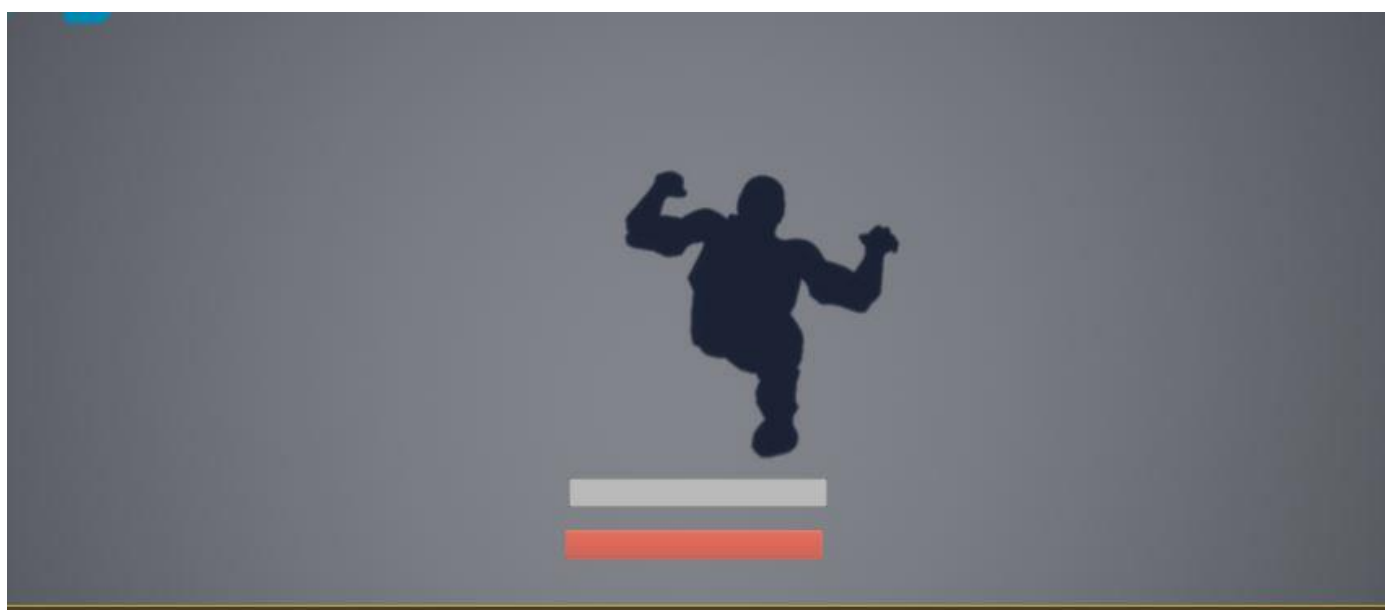

Gambar 4. Camera view dari Player 


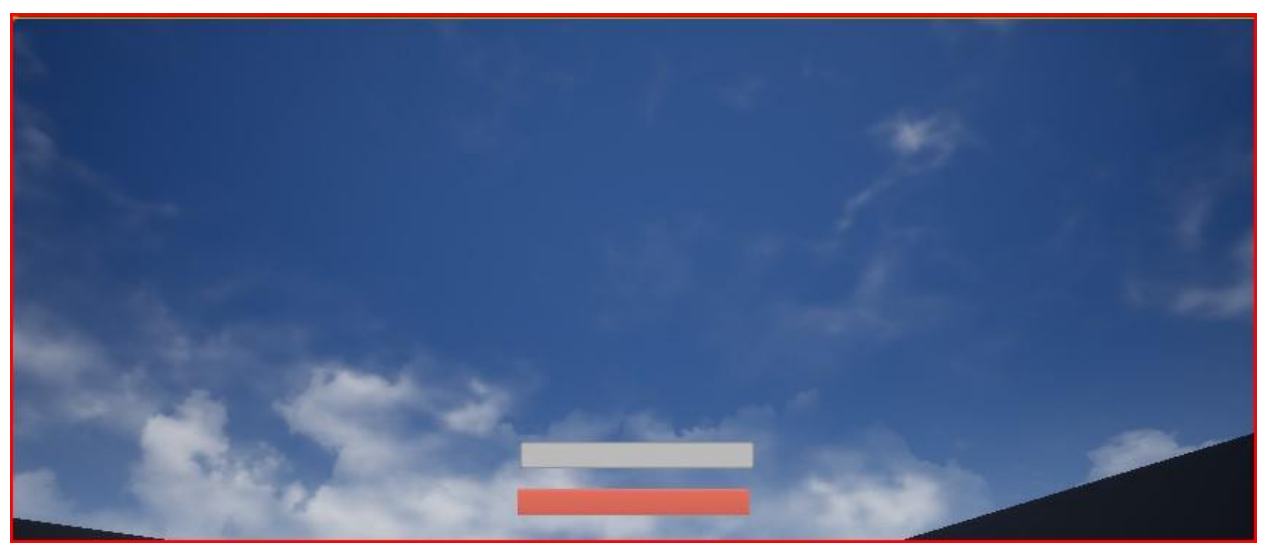

Gambar 5. Indikator health dan armor

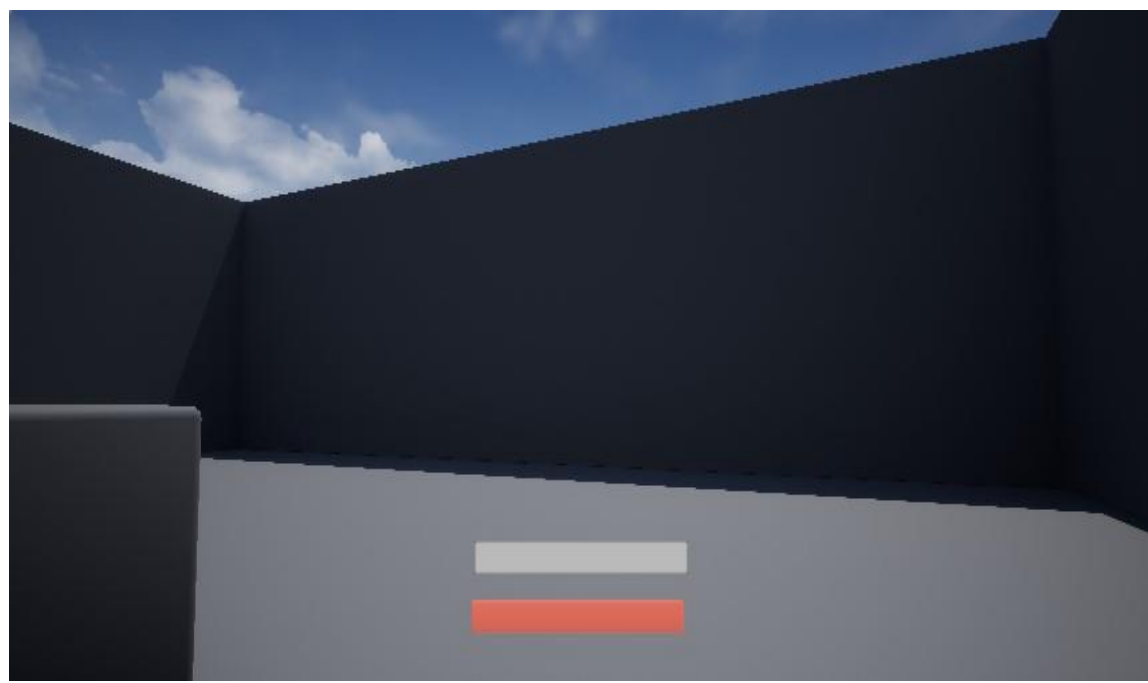

Gambar 6. Camera view dari Player

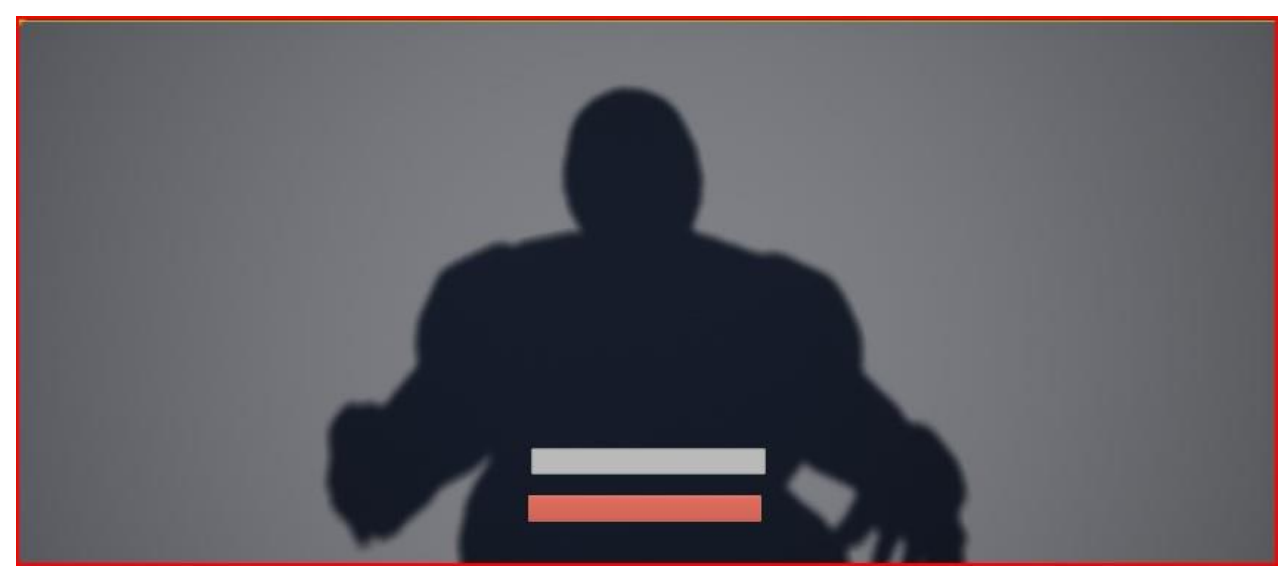

Gambar 7. Camera view dari Player 
Game 3d Perjuangan Rakyat Surabaya Dalam Pertempuran 10 November 1945 Dengan Belanda Menggunakan Unreal Engine

Game ini memiliki prinsip kerja sebagai berikut:

1. Mulai

2. Install aplikasi

3. Buka atau jalankan aplikasi

4. Pilih senjata yang akan digunakan (Bambu runcing / Brand)

5. Masuk ke permainan

6. Jika pemain kalah dengan NPC (Non Playable Character / Musuh dari pemain), permainan mulai ulang dengan pilih senjata

7. Jika pemain menang dengan NPC, permainan tetap berlanjut sampai selesai

8. Selesai

\section{Kesimpulan}

Dari penulisan ini penulis mengharapkan dapat memberi beberapa manfaat. Adapun manfaat dari penulisan tugas akhir ini adalah edukasi warga Surabaya umumnya untuk mengenang pertempuran 10 november 1945. Dengan adanya game ini diharapkan masyarakat, khususnya di surabaya bisa teredukasi sejarah perjuangan pertempuran 10 November 1945, dengan mengenal senjata yang digunakan waktu pertempuran itu dan tetap mejaga semangat saat itu di masa kini dengan tidak melupakan sejarah perjuangan para pahlawan dan terus bekarya untuk bangsa dan negeri. 


\section{Referensi}

Efendi, Y. (2018). Rancangan Aplikasi Game Edukasi Berbasis Mobile Menggunakan App Inventor. Jurnal Intra-Tech, 2(1), 41.

Epic Games inc. (2020). Make Something Unreal. Unreal Engine. https://www.unrealengine.com/en-US/

Harsadi, P. (2016). Pathfinding pada Lingkungan Statis Berdasarkan Artificial Potential Field Dengan Flocking Behavior Untuk Non-Player Character Follower Pada Game. Jurnal Ilmiah SINUS, March 2016, 1-10. https://doi.org/10.30646/sinus.v14i1.233

Ibeng, P. (2020). Pengertian Software, Fungsi, Jenis, Contoh dan Menurut Ahli. Pendidikan.co.id. https://pendidikan.co.id/pengertian-software-fungsi-jeniscontoh-dan-menurut-ahli

Irawan, A., Risa, M., \& Noor, T. (2018). Remastering Sistem Operasi Android Untuk Peningkatan Performa Pada Lenovo A6000 Plus. POSITIF : Jurnal Sistem dan Teknologi Informasi, 4(1), 12. https://doi.org/10.31961/positif.v4i1.530

Lamanto, S. A. (2016). PENANAMAN KESADARAN SEJARAH DAN SIKAP NASIONALISME DALAM PEMBELAJARAN SEJARAH DI SMA NEGERI 2 BANGGAI. Istoria : Jurnal Pendidikan dan Sejarah, 12(1), 87-96.

Lubis, I. R., Solihah, M., Sugiyarto, K. H., \& Ikhsan, J. (2015). Pengembangan Media Mobile Learning "CHEMONDRO” Berbasis android sebagai suplemen belajar siswa SMA. Seminar Nasional Pendidikan Sains "Pengembangan Model dan Perangkat Pembelajaran untuk Meningkatkan Kemampuan Berpikir Tingkat Tinggi," November, 468-477.

Miranda, P. H., Waluyanto, H. D., \& Zacky, A. (2018). Perancangan Buku Komik sebagai Media Informasi Mengenai Dampak Game Terhadap Perilaku Sosial Anak. Jurnal DKV Adiwarna, 1(1), 1-9.

Moshinsky, M. (1959). Sejarah Game. Nucl. Phys., 13(1), 104-116.

Muzakkiyah, I. (2019). PERANGKAT LUNAK PADA LEMBAGA INFORMASI. Baca Mau Tak Baca Rindu.

https://blog.ub.ac.id/iftakhmuzakkiyah98/2019/09/05/perangkat-lunak-padalembaga-informasi/

Prasetiyo, Y. M., Setiabudi, D. H., \& Purbowo, A. N. (2018). Game Battleship Menggunakan Metode BFS dan Database Firebase Dengan Unity Pada Android. Jurnal Infra, 6(2), 2-6.

Ramadhani, S. (2020). PERANGKAT LUNAK KOMPUTER. OSF.io. https://doi.org/10.31219/osf.io/97b5c

Rasjid, F. E. (2010). Android: Sistem Operasi Pada Smartphone. Universitas Surabaya (UBAYA).

https://www.ubaya.ac.id/2018/content/articles_detail/7/Android--SistemOperasi-pada-Smartphone.html

Ricyono, A., Arifin, Z., \& Kridalaksana, A. H. (2019). Game Ed-Puzzle Berbasis Android Dengan Menggunakan Metode Simple Multi Attribute Rating Technique. Prosiding SAKTI (Seminar Ilmu Komputer dan Teknologi Informasi), 4(2), 91-96.

Setiawan, E. (2016). Kamus Besar Bahasa Indonesia (KBBI) (Ver.Daring). Balai Pengembangan dan Pembinaan Bahasa Kemdikbud. www.kbbi.web.id Syuhada, A. (2014). Perancangan Aplikasi Game Rancang Bangun Angka 
Menggunakan Metode Exact String Matching. Pelita Informatika Budi Darma, 0911058, 1-6.

Walelang, A. V., Liliana, L., \& Budhi, G. S. (2015). Game Pembelajaran Fisika

Dengan Game Bertipe Adventure Game. Jurnal Infra, 3(2), 346-352. 